\title{
Regulation of skeletal muscle sucrose, non-fermenting 1/AMP-activated protein kinase-related kinase (SNARK) by metabolic stress and diabetes
}

\author{
A. Rune • M. E. Osler • T. Fritz • J. R. Zierath
}

Received: 18 May 2009/Accepted: 18 June 2009/Published online: 4 August 2009

(C) The Author(s) 2009. This article is published with open access at Springerlink.com

\begin{abstract}
Aims/hypothesis Sucrose, non-fermenting 1/AMP-activated protein kinase-related kinase (SNARK) is involved in cellular stress responses linked to obesity and type 2 diabetes. We determined the role of SNARK in response to metabolic stress and insulin action on glucose and lipid metabolism in skeletal muscle.

Methods Vastus lateralis skeletal muscle biopsies were obtained from normal glucose tolerant $(n=35)$ and type 2 diabetic $(n=31)$ men and women for SNARK expression studies. Primary myotube cultures were derived from biopsies obtained from normal glucose tolerant individuals for metabolic studies.

Results SNARK (also known as NUAK2) mRNA expression was unaltered between normal glucose tolerant individuals and type 2 diabetic patients. SNARK expression was increased in skeletal muscle from obese (BMI $>31 \mathrm{~kg} / \mathrm{m}^{2}$ ) normal glucose tolerant individuals and type 2 diabetic patients (1.4- and 1.4-fold, respectively, $p<0.05)$ vs overweight $\left(\mathrm{BMI}<28 \mathrm{~kg} / \mathrm{m}^{2}\right.$ ) normal glucose tolerant individuals and type 2 diabetic patients. SNARK mRNA was increased in myotubes exposed to palmitate (12-fold; $p<0.01)$, or TNF- $\alpha(25$-fold, $p<0.05)$, but not to oleate, glucose or IL-6, whereas expression of the AMP-activated protein kinase $\alpha 2$ subunit was unaltered. Small interfering
\end{abstract}

\footnotetext{
A. Rune $\cdot$ M. E. Osler $\cdot$ J. R. Zierath $(\bowtie)$

Section of Integrative Physiology, Department of Molecular

Medicine and Surgery, Karolinska Institutet,

von Eulers väg 4a,

17177 Stockholm, Sweden

e-mail: Juleen.Zierath@ki.se

T. Fritz

Center of Family Medicine, Karolinska Institutet,

Huddinge, Sweden
}

(si)RNA against SNARK reduced mRNA and protein in myotubes by $61 \%$ and $60 \%$, respectively $(p<0.05)$. SNARK siRNA was without effect on basal or insulinstimulated glucose uptake or lipid oxidation, and insufficient to rescue TNF- $\alpha$ - or palmitate-induced insulin resistance.

Conclusions/interpretation Skeletal muscle SNARK expression is increased in human obesity, and in response to metabolic stressors, but not type 2 diabetes. Partial SNARK depletion failed to modify either glucose or lipid metabolism, or protect against $\mathrm{TNF}-\alpha$ - or palmitate-induced insulin resistance in primary human myotubes.

Keywords AMPK activation · Glucose metabolism · Insulin resistance $\cdot$ Lipid metabolism $\cdot$ Obesity $\cdot$ Palmitate $\cdot$ Signal transduction $\cdot \operatorname{siRNA} \cdot$ TNF- $\alpha \cdot$ Type 2 diabetes

\author{
Abbreviations \\ AICAR 5-Aminoimidazole-4-carboxamide-1 $\beta$-4-ribo- \\ furanoside \\ AMPK AMP-activated protein kinase \\ IR Insulin resistance \\ siRNA Small interfering RNA \\ SNARK Sucrose, non-fermenting 1/AMP-activated \\ protein kinase-related kinase
}

\section{Introduction}

The ability to adjust energy use and storage in times of fuel surplus or deficiency is vital for survival throughout evolution. AMP-activated protein kinase (AMPK) is known as a master regulator of glucose and lipid metabolism in mammals through sensing of the ratio of AMP:ATP in the 
cell $[1,2]$. Upon activation of AMPK, anabolic energydemanding pathways are switched off and catabolic ATPproducing pathways are activated, thereby controlling peripheral glucose and lipid homeostasis. Recently, a family of AMPK-related kinases has been described, thereby broadening the regulation of metabolism in response to cellular stress to include novel protein kinases [3].

AMPK is a heterotrimeric complex consisting of a catalytic AMP-sensitive $\alpha$ subunit and regulatory $\beta$ and $\gamma$ subunits. Twelve protein kinases (BRSK1, BRSK2, NUAK1, NUAK2, QIK, QSK, SIK, MARK1, MARK2, MARK3, MARK4 and MELK) closely related to $\mathrm{AMPK} \alpha_{1}$ and $\mathrm{AMPK} \alpha_{2}$ have been identified in the human kinome, thus forming a 14 kinase phylogenetic tree known as 'AMPK-related kinases' [3, 4]. LKB1, an upstream activating kinase of AMPK, phosphorylates and activates 11 of the AMPKrelated kinases [3]. Although the role of AMPK-related kinases is largely unknown, they do not appear to interact with the regulatory $\beta$ and $\gamma$ subunits of AMPK [5]. Furthermore, the majority of the AMPK-related kinases are not activated by AMP or pharmacological activators of AMPK including 5-aminoimidazole-4-carboxamide-1 $\beta$-4ribofuranoside (AICAR) and phenformin [3, 6]. Recent evidence suggests that skeletal muscle-selective knockout of LKB1 increases insulin sensitivity [7], possibly implicating these novel AMPK-related protein kinases in the regulation of glucose homeostasis.

Haploinsufficient Snark (also known as Nuak2) knockout mice develop obesity, hepatic steatosis, altered serum lipid profiles, hyperinsulinaemia, hyperglycaemia and impaired glucose tolerance with age [8]. SNARK was first identified as an ultraviolet B-induced gene in keratinocytes [9]. SNARK is located on human chromosome 1q32 and is translated into a single protein of approximately $76 \mathrm{kDa}$ [10]. In rats, Snark is expressed in multiple tissues, with highest expression in kidney [11]. Sucrose, non-fermenting
1/AMP-activated protein kinase-related kinase (SNARK) is activated in a cell-type-specific manner by a variety of stressors including hyperosmotic stress, DNA damage and oxidative stress, as well as nutrients including glucose and glutamine [10, 11]. Several aspects of SNARK activation and regulation are broadly similar to AMPK [12]. For example, SNARK and AMPK are both AMP-responsive and activated by treatments known to increase the AMP: ATP ratio, including glucose deprivation and chemical ATP production $[10,11,13]$. Nevertheless, the metabolic role of SNARK, particularly in humans and at the cellular level in skeletal muscle, is incompletely resolved.

Given that Snark-haploinsufficient mice become obese and glucose-intolerant [8], this AMPK-related protein kinase may play a permissive role in energy metabolism. Thus, we tested the hypothesis that SNARK is involved in cellular stress responses associated with obesity and type 2 diabetes. Since skeletal muscle plays an important role in the regulation of whole-body glucose uptake, the aim of this study was to determine the role of SNARK in response to metabolic stress and insulin action on glucose and lipid metabolism in human skeletal muscle.

\section{Methods}

Study participants and muscle biopsy procedure Biopsies were obtained using a Weil-Blakesley conchotome from vastus lateralis skeletal muscle under local anaesthesia (lidocaine hydrochloride $5 \mathrm{mg} / \mathrm{ml}$ ) from normal glucose tolerant and type 2 diabetic men and women for mRNA expression analysis of the gene encoding SNARK. Biopsies were snap-frozen and stored in liquid nitrogen until use. The clinical characteristics of the study participants are presented in Table 1. HOMA2-insulin resistance (IR) values were determined using the HOMA calculator (www.dtu.ox.ac.uk).

Table 1 Participant characteristics

\begin{tabular}{|c|c|c|c|c|c|c|c|c|}
\hline & Sex & Age (years) & $\begin{array}{l}\mathrm{BMI} \\
\left(\mathrm{kg} / \mathrm{m}^{2}\right)\end{array}$ & $\begin{array}{l}\text { Fasting glucose } \\
(\mathrm{mmol} / \mathrm{l})\end{array}$ & $\begin{array}{l}\mathrm{HbA}_{1 \mathrm{c}} \\
(\%)\end{array}$ & $\begin{array}{l}\text { Triacylglycerol } \\
(\mathrm{mmol} / \mathrm{l})\end{array}$ & $\begin{array}{l}\text { Insulin } \\
(\mathrm{pmol} / \mathrm{l})\end{array}$ & HOMA2-IR \\
\hline \multicolumn{9}{|c|}{ Normal glucose tolerant } \\
\hline $\mathrm{BMI}<28 \mathrm{~kg} / \mathrm{m}^{2}$ & $10 \mathrm{~F} / 8 \mathrm{M}$ & $59 \pm 1$ & $26.2 \pm 0.2$ & $5.3 \pm 0.1$ & $4.6 \pm 0.05$ & $1.15 \pm 0.14$ & $51.2 \pm 9.2$ & $1.0 \pm 0.2$ \\
\hline BMI $>31 \mathrm{~kg} / \mathrm{m}^{2}$ & $11 \mathrm{~F} / 6 \mathrm{M}$ & $61 \pm 1$ & $34.4 \pm 0.9^{*}$ & $5.5 \pm 0.1$ & $4.8 \pm 0.07^{*}$ & $1.49 \pm 0.14$ & $59.7 \pm 7.1$ & $1.1 \pm 0.1$ \\
\hline \multicolumn{9}{|l|}{ Type 2 diabetic } \\
\hline $\mathrm{BMI}<28 \mathrm{~kg} / \mathrm{m}^{2}$ & $2 \mathrm{~F} / 12 \mathrm{M}$ & $60 \pm 1$ & $27.0 \pm 0.3 *$ & $7.8 \pm 0.4^{*}$ & $6.1 \pm 0.23^{*}$ & $1.34 \pm 0.13$ & $53.0 \pm 6.5$ & $1.1 \pm 0.1$ \\
\hline $\mathrm{BMI}>31 \mathrm{~kg} / \mathrm{m}^{2}$ & $3 \mathrm{~F} / 14 \mathrm{M}$ & $60 \pm 1$ & $34.5 \pm 0.8^{*}$ & $7.8 \pm 0.4^{*}$ & $5.9 \pm 0.19^{*}$ & $1.53 \pm 0.10^{*}$ & $91.4 \pm 11.5^{*}$ & $1.9 \pm 0.21 *$ \\
\hline
\end{tabular}

Data are means $\pm \mathrm{SE}$

${ }^{*} p<0.05$ compared with normal glucose tolerant individuals with $\mathrm{BMI}<28 \mathrm{~kg} / \mathrm{m}^{2}$

$\mathrm{F}$, female; $\mathrm{M}$, male 
The regional ethical committee at Karolinska Institutet approved all study protocols. Informed written and verbal consent was received from all study participants.

Skeletal muscle cell cultures and in vitro treatments Skeletal muscle cell cultures were established from satellite cells isolated from vastus lateralis skeletal muscle biopsies obtained from normal glucose tolerant individuals. Satellite cells were isolated by trypsin-EDTA digestion, and myoblasts were cultured and differentiated into myotubes as previously described [14]. Myotubes were used to test the effects of a variety of cellular stressors, including nutrients, hormones or cytokines, on SNARK mRNA expression. Myotubes were treated with palmitate $(0.25 \mathrm{mmol} / \mathrm{l})$, oleate $(0.25 \mathrm{mmol} / \mathrm{l})$, glucose $(25 \mathrm{mmol} / \mathrm{l}), \mathrm{TNF}-\alpha(20 \mathrm{ng} / \mathrm{ml})$ or IL-6 $(20 \mathrm{ng} / \mathrm{ml})$ for 2 or 7 days. SNARK mRNA expression was determined as described below.

To determine the direct role of SNARK on basal and insulin-stimulated glucose and lipid metabolism, myoblasts were transfected with small interfering (si) RNA against a scrambled non-specific sequence or SNARK (80 pmol) (Ambion/Applied Biosystems, Foster City, USA) for $16 \mathrm{~h}$ before initiation of differentiation and also after 2 days into the differentiation programme using Lipofectamine 2000 (Invitrogen, Carlsbad, CA, USA) in serum- and antibioticfree DMEM [15]. Glucose incorporation into glycogen and lipid oxidation were determined, as described below.

SNARK mRNA expression SNARK mRNA expression was assessed in vastus lateralis skeletal muscle biopsies or primary skeletal muscle cell cultures (myotubes) using quantitative RT-PCR (ABI PRISM 7000 Sequence Detector System; Applied Biosystems). Total RNA was purified from skeletal muscle biopsies using Trizol reagent (Invitrogen, Carlsbad, CA, USA) and from myotubes using an RNeasy Mini Kit (Invitrogen). Purified RNA was treated with DNase I using a DNA-free kit (Ambion) and cDNA synthesis was performed with a SuperScript First Strand Synthesis System (Invitrogen). TaqMan gene expression assays (Hs00388292_m1 and Hs00178903_m1) for SNARK and $A M P K \alpha 2$ (also known as PRKAA2) mRNA expression were independently used in multiplex, with $\beta 2$-microglobulin as a reference gene (Applied Biosystems). All samples where assayed in duplicate. The mRNA relative abundance was calculated using the standard curve method as described by Applied Biosystems.

Glycogen synthesis in skeletal muscle cells Glucose incorporation into glycogen was determined as described [16]. Myotubes were incubated in the absence or presence of either 6 or $60 \mathrm{nmol} / \mathrm{l}$ insulin for $30 \mathrm{~min}$ and thereafter incubated for 90 min with D-[U- $\left.{ }^{14} \mathrm{C}\right]$ glucose $(3700 \mathrm{~Bq} / \mathrm{ml}$; Amersham, Uppsala, Sweden) in DMEM (1 g glucose/l). When indicated, myotubes were exposed to either palmitate $(0.25 \mathrm{mmol} / \mathrm{l})$ or TNF- $\alpha$ (20 ng/ml) for $48 \mathrm{~h}$ before the experiment was performed. Experiments were performed in duplicate. Results are reported as nmol glucose (mg protein $)^{-1} \mathrm{~h}^{-1}$.

Lipid oxidation in skeletal muscle cells NEFA oxidation was assessed by exposing myotubes to $\left[{ }^{3} \mathrm{H}\right]$ palmitic acid and measuring the production of ${ }^{3} \mathrm{H}$-labelled water. Myotubes were cultured in six well plates and serum starved overnight. Cells were washed once with PBS and incubated for $5.5 \mathrm{~h}$ with $1 \mathrm{ml}$ DMEM (1 g glucose/1), supplemented with fatty acid-free $\operatorname{BSA}\left(0.2 \% \mathrm{wt} / \mathrm{vol}\right.$.) and $\left[9,10(n)-{ }^{3} \mathrm{H}\right]$ palmitic acid $(1850 \mathrm{~Bq} / \mathrm{ml}$; Amersham), with or without insulin (120 nmol/l) or AICAR (1 mmol/l; Toronto Research Chemicals, Toronto, ON, Canada). To absorb non-metabolised palmitate, $0.2 \mathrm{ml}$ of the cell supernatant was mixed with $0.8 \mathrm{ml}$ charcoal slurry $(0.1 \mathrm{~g}$ charcoal powder in $1 \mathrm{ml} 0.02 \mathrm{~mol} / \mathrm{l}$ TRIS-HCl buffer, $\mathrm{pH} 7.5$ ) in a $2 \mathrm{ml}$ Eppendorf tube and shaken for $30 \mathrm{~min}$. Samples were subjected to centrifugation at $18,500 \times \mathrm{g}$ for $15 \mathrm{~min}$, after which $0.3 \mathrm{ml}$ supernatant with ${ }^{3} \mathrm{H}$-labelled-bound water was withdrawn, and radioactivity was determined by liquid scintillation counting (WinSpectral 1414 Liquid Scintillation Counter; Wallac, Turku, Finland). Each experiment was performed in duplicate. Results are reported as per cent converted palmitate (mg protein) $)^{-1} \mathrm{~h}^{-1}$.

Western blot analysis Lysates were prepared from myotubes transfected with siRNA against a scrambled sequence or SNARK. Proteins were separated by SDS-PAGE and subjected to immunoblot analysis with an antibody directed against SNARK (Proteintech, Manchester, UK). Proteins where visualised by enhanced chemiluminescence and quantified by densiometry. Results are reported as arbitrary units and normalised to a loading control (desmin).

Statistics Results are presented as means \pm SE. Differences between groups were determined by Student's $t$ test or twoway ANOVA. When ANOVA was applied, pair-wise multiple comparison procedures were performed using the Holm-Sidak method at a significance level of 0.05 .

\section{Results}

Skeletal muscle SNARK $m R N A$ expression is increased with obesity but not in diabetes SNARK mRNA expression was determined in vastus lateralis skeletal muscle biopsies from normal glucose tolerant and type 2 diabetic men and women (Fig. 1). Type 2 diabetic patients had fasting hyperglycaemia, and elevated $\mathrm{HbA}_{1 \mathrm{c}}$ levels, compared with normal glucose tolerant individuals $(p<0.05)$. Individuals 


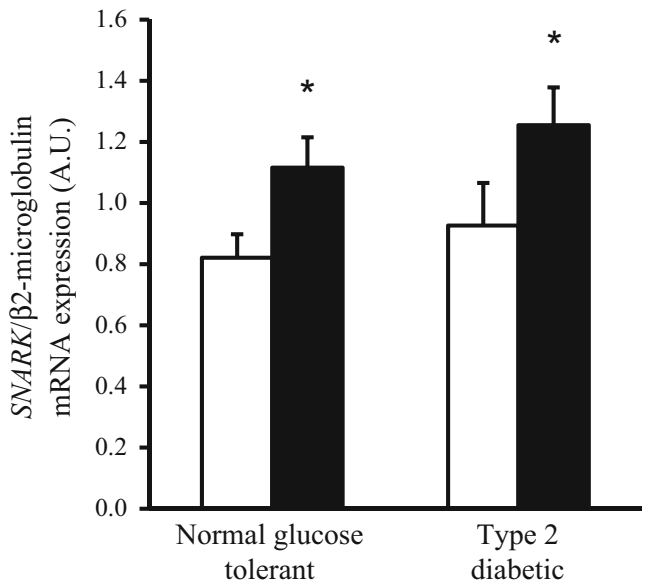

Fig. 1 SNARK mRNA expression was determined in vastus lateralis skeletal muscle biopsies from normal glucose tolerant individuals and type 2 diabetic patients with BMI $<28 \mathrm{~kg} / \mathrm{m}^{2}$ (white bars) and BMI $>31 \mathrm{~kg} / \mathrm{m}^{2}$ (black bars). Result are reported in arbitrary units (A.U.) as means \pm SE for $n=14-18$ individuals. ${ }^{*} p<0.05$ compared with normal glucose tolerant individuals with BMI $<28 \mathrm{~kg} / \mathrm{m}^{2}$

were stratified into two groups based on BMI. The metabolic derangements were exacerbated in the obese $\left(\mathrm{BMI}>31 \mathrm{~kg} / \mathrm{m}^{2}\right)$ vs overweight $\left(\mathrm{BMI}<28 \mathrm{~kg} / \mathrm{m}^{2}\right.$ ) type 2 diabetic patients, who also had increased HOMA2-IR values $(p<0.05)$. SNARK mRNA expression was increased 1.4-fold in obese normal glucose tolerant individuals (BMI $>31 \mathrm{~kg} / \mathrm{m}^{2}$ ) vs overweight normal glucose tolerant individuals (BMI $<28 \mathrm{~kg} / \mathrm{m}^{2}$ ). SNARK mRNA was also increased 1.4-fold in obese type 2 diabetic patients (BMI $>31 \mathrm{~kg} / \mathrm{m}^{2}$ ) vs overweight type 2 diabetic patients (BMI $<28 \mathrm{~kg} / \mathrm{m}^{2}$ ). SNARK mRNA expression was similar in normal glucose tolerant and type 2 diabetic patients, irrespectively of BMI.

Effects of cellular stressors on SNARK mRNA expression SNARK mRNA expression was assessed in cultured myotubes treated with a variety of nutrients or cytokines for 2 days (Fig. 2a). Exposure of myotubes to either palmitate (12-fold; $p<0.01)$ or TNF- $\alpha$ ( 25 -fold, $p<0.05$ ), but not oleate, glucose or IL-6, increased SNARK mRNA expression compared with untreated myotubes, whereas expression of the $A M P K \alpha 2$ subunit was unaltered (Fig. 2b). Similar responses on SNARK mRNA expression were also observed in myotubes exposed to these metabolic stressors for 7 days (data not shown). Furthermore, SNARK mRNA expression was unaltered following exposure of myotubes to AMPK activators, including AICAR, metformin or rosiglitazone (data not shown).

SNARK silencing in myotubes The effect of SNARK gene silencing on mRNA expression (Fig. 3a) and protein level (Fig. 3b) was determined in cultured myotubes. siRNA against SNARK reduced mRNA expression by $61 \%$ and protein content by $60 \%$ compared with myotubes transfected with siRNA against a scrambled sequence.

Role of SNARK on glucose incorporation into glycogen Glucose incorporation into glycogen was assessed in myotubes transfected with siRNA against a scrambled sequence or SNARK (Fig. 4). Insulin increased glucose incorporation into glycogen in myotubes transfected with siRNA against a scrambled sequence (1.8- and 2.3-fold in the presence of 6 or $60 \mathrm{nmol} / 1$ insulin, respectively; $p<0.05$ vs basal). Similar effects of insulin on glucose incorporation into glycogen were noted for myotubes transfected with siRNA against SNARK (1.8- and 2.4-fold increase in the presence of 6 or $60 \mathrm{nmol} / 1$ insulin, respectively; $p<0.05$ vs basal). $S N A R K$ silencing did not influence basal and insulinstimulated glucose incorporation into glycogen.

Role of SNARK on lipid oxidation Lipid oxidation was determined in myotubes transfected with siRNA against a scrambled sequence or SNARK (Fig. 5). Insulin suppressed

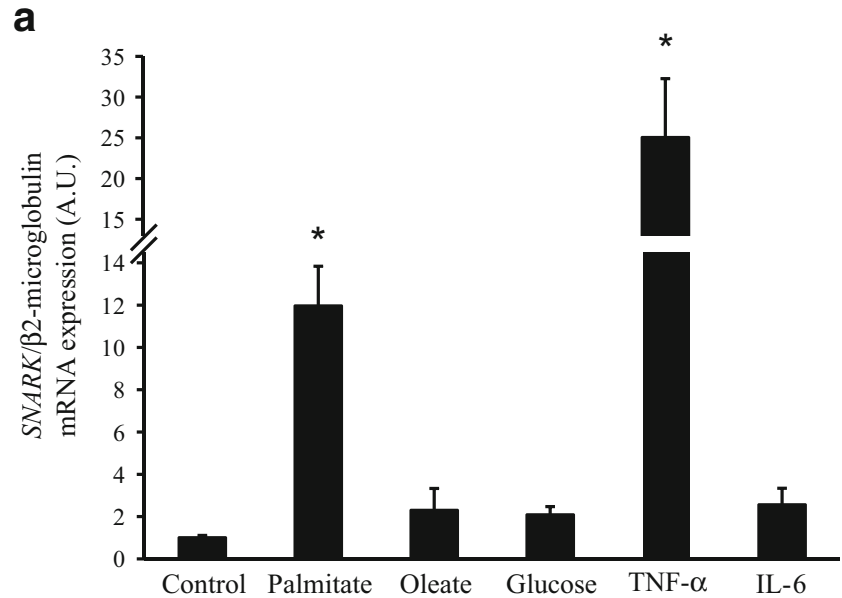

b

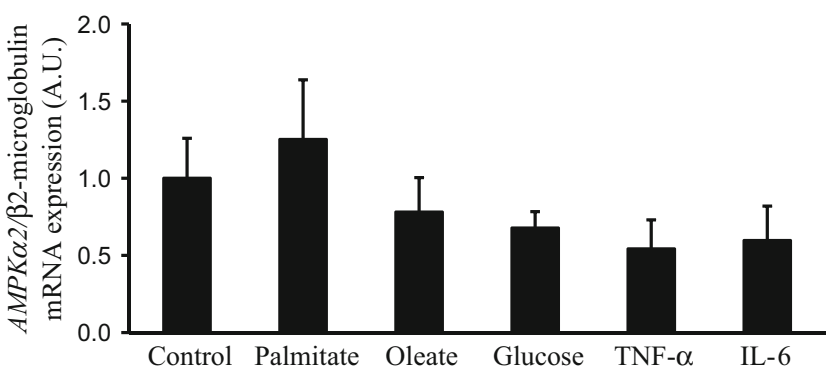

Fig. 2 Effect of cellular stressors on SNARK mRNA expression. Cultured myoblasts were treated with palmitate $(0.25 \mathrm{mmol} / \mathrm{l})$, oleate $(0.25 \mathrm{mmol} / \mathrm{l})$, glucose $(25 \mathrm{mmol} / \mathrm{l}), \mathrm{TNF}-\alpha(20 \mathrm{ng} / \mathrm{ml})$ or IL-6 $(20 \mathrm{ng} /$ $\mathrm{ml}$ ) for 2 days followed by assessment of SNARK mRNA expression (a) and $A M P K \alpha 2$ mRNA expression (b). Results are reported in arbitrary units (A.U.) as means $\pm \mathrm{SE}$ for $n=5$ individual cultures. $* p<0.05$ compared with unstimulated control cells 


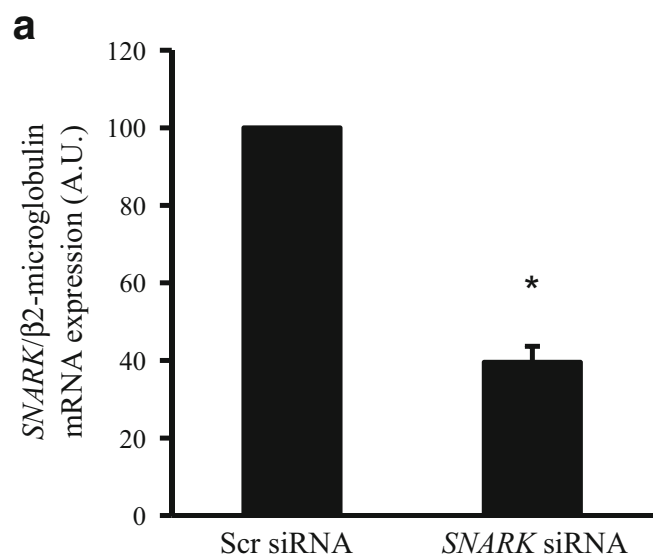

b

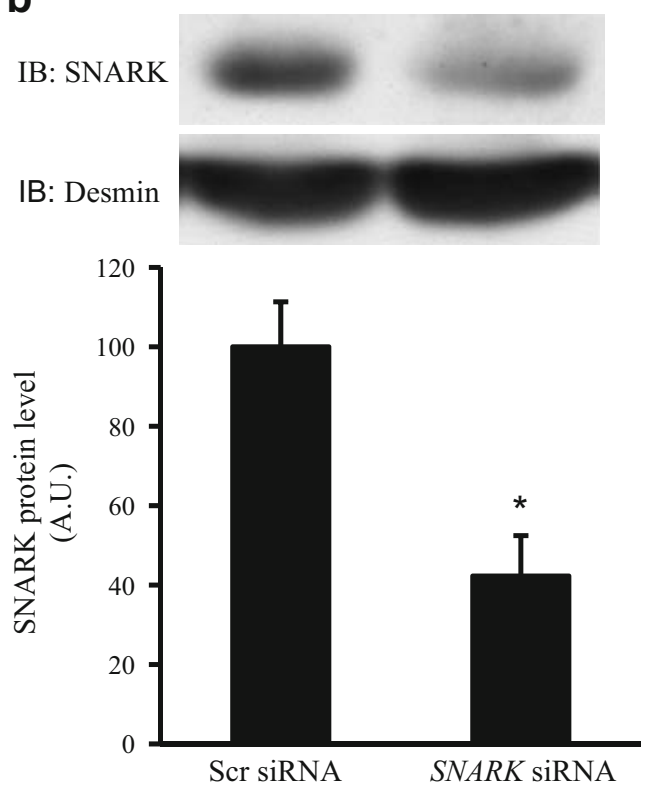

Fig. $3 S N A R K$ gene silencing in primary human myotubes. The effect of SNARK siRNA was determined on mRNA expression (a) and protein levels (b). Results are reported in arbitrary units (A.U.) as means \pm SE for $n=4$ individual cultures. ${ }^{*} p<0.05$ compared with myotubes treated with siRNA against a scrambled (Scr) sequence. IB, immunoblot

lipid oxidation in myotubes transfected with siRNA against a scrambled sequence $(14 \% ; p<0.05)$ and this effect was unaltered by SNARK silencing. AICAR increased lipid oxidation in myotubes transfected with siRNA against either a scrambled sequence (3.5-fold; $p<0.01)$ or SNARK (3.2-fold; $p<0.01)$ vs the basal condition. Thus, SNARK silencing did not influence basal or insulin- or AICARstimulated lipid oxidation.

Effect of SNARK silencing on TNF- $\alpha$ - or palmitate-induced insulin resistance Given that TNF- $\alpha$ and palmitate treatment markedly increased SNARK mRNA expression, we also examined whether protein levels were altered under these conditions (Fig. 6a). Exposure of myotubes to either

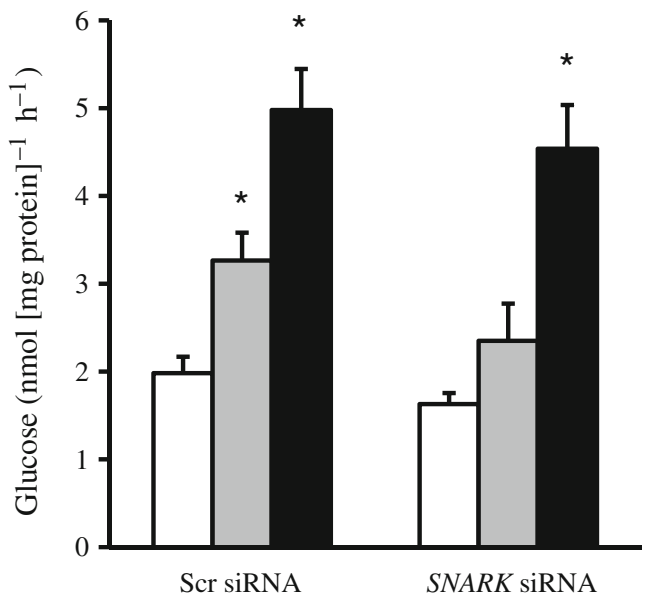

Fig. 4 Role of $S N A R K$ in glucose incorporation into glycogen. Glucose incorporation into glycogen was measured in myotubes transfected with either siRNA against a scrambled sequence (Scr) or SNARK and incubated in the absence (basal; white bars) or presence of a submaximal ( $6 \mathrm{nmol} / \mathrm{l}$; grey bars) or maximal $(60 \mathrm{nmol} / \mathrm{l}$; black bars) concentration of insulin. Results are means \pm SE for $n=8$ individual cultures. ${ }^{*} p<0.05$ compared with basal scrambled siRNA-transfected myotubes

TNF- $\alpha$ or palmitate for $48 \mathrm{~h}$ increased SNARK protein content $(p<0.05)$. SNARK silencing reduced protein content by $56 \%(p<0.05)$, and completely prevented the effect of either TNF- $\alpha$ or palmitate to increase SNARK protein.

Exposure of myotubes to TNF- $\alpha$ or palmitate induces insulin resistance in cultured human myotubes [17, 18], coincident with increased SNARK expression (Fig. 2a). Thus, we determined whether SNARK silencing prevents insulin resistance arising from these factors (Fig. 6b).

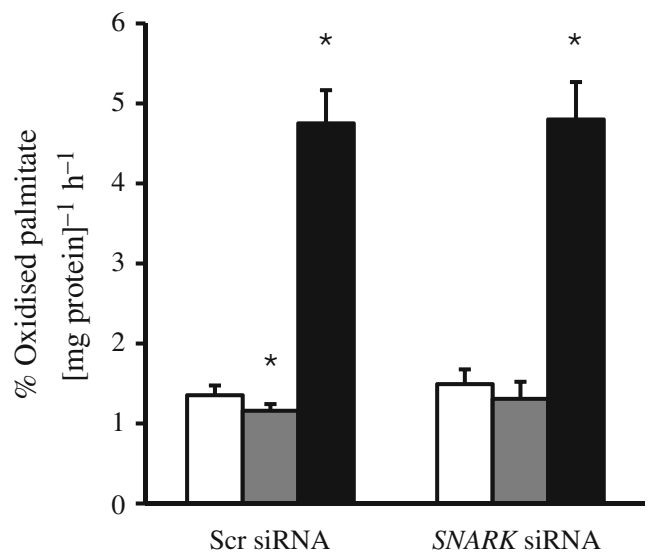

Fig. 5 Role of SNARK in lipid oxidation. Lipid oxidation was measured in myotubes transfected with siRNA against either a scrambled sequence (Scr) or SNARK and incubated in the absence (basal; white bars) or presence of either insulin $(60 \mathrm{nmol} / \mathrm{l}$; grey bars $)$ or $\operatorname{AICAR}(1 \mathrm{mmol} / \mathrm{l}$; black bars). Results are means \pm SE for $n=$ 8 individual cultures. $* p<0.05$ compared with basal scrambled siRNA-transfected myotubes 
a

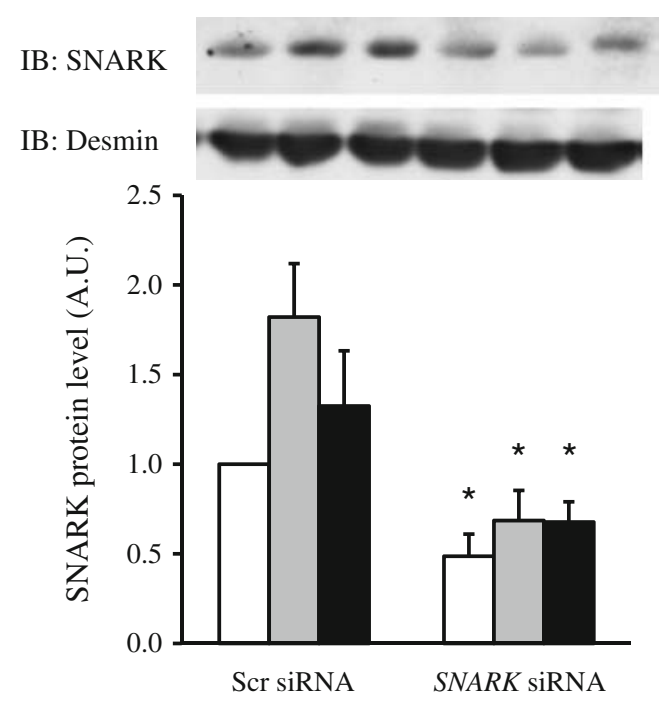

b

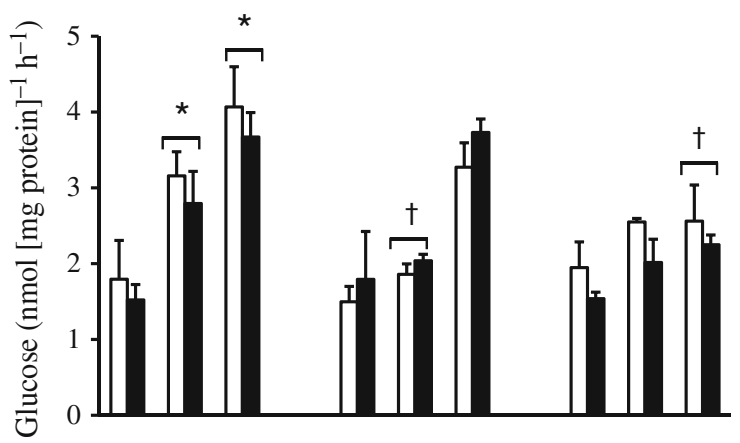

\begin{tabular}{|c|c|c|c|c|c|c|c|c|}
\hline Insulin $(\mathrm{nmol} / \mathrm{l})$ & 0 & 6 & 60 & 0 & 6 & 60 & 0 & 6 \\
\hline TNF- $\alpha$ & . & - & - & + & + & + & - & - \\
\hline Palmitate & - & - & - & - & - & - & 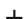 & + \\
\hline
\end{tabular}

Fig. 6 Effect of SNARK silencing on TNF- $\alpha$ - and palmitate-induced insulin resistance. Human myotubes were transfected with either siRNA against a scrambled sequence (Scr) or SNARK and incubated in the absence (basal; white bars) or presence of TNF- $\alpha$ ( $20 \mathrm{ng} / \mathrm{ml}$; grey bars) or palmitate $(0.25 \mathrm{nmol} / \mathrm{l}$; black bars) for $48 \mathrm{~h}$ and the effect of $S N A R K$ siRNA silencing was determined on protein levels (a). Glucose incorporation into glycogen was measured in the absence or presence of insulin (b) in myotubes transfected with siRNA against Scr (white bars) or $S N A R K$ (black bars). Results are means \pm SE for $n=4$ individual cultures. ${ }^{*} p<0.05$ compared with myotubes incubated in the absence of insulin. $\dagger p<0.05$ compared with myotubes incubated in the absence of TNF- $\alpha$ and palmitate (basal). A.U. arbitrary units; IB, immunoblot

Myotubes were transfected with siRNA against either a scrambled sequence or SNARK and incubated for $48 \mathrm{~h}$ in the absence or presence of TNF- $\alpha(20 \mathrm{ng} / \mathrm{ml})$ or palmitate $(0.25 \mathrm{mmol} / \mathrm{l})$. TNF- $\alpha$ exposure decreased insulinstimulated glucose incorporation into glycogen by $41 \%$ in the presence of $6 \mathrm{nmol} / 1(p<0.05)$, but not $60 \mathrm{nmol} / 1$ insulin, in myotubes treated with siRNA against either a scrambled sequence or SNARK. Thus, siRNA against SNARK does not protect against TNF- $\alpha$-induced insulin resistance. Palmitate exposure decreased insulin-stimulated glucose incorpora- tion into glycogen by $37 \%$ in the presence of $60 \mathrm{nmol} /$ 1 insulin $(p<0.01)$, but not $6 \mathrm{nmol} / 1$ insulin, in myotubes treated with siRNA against either a scrambled sequence or SNARK. Thus, siRNA against SNARK does not protect against palmitate-induced insulin resistance.

\section{Discussion}

The AMPK-related kinase SNARK plays a role in wholebody glucose and energy homeostasis [8]. Whole-body Snark-haploinsufficient mice are obese and glucoseintolerant, implicating an important role for this AMPKrelated protein kinase in the regulation of energy and glucose homeostasis [8]. Here we tested the hypothesis that SNARK is involved in cellular stress responses linked to the development of insulin resistance in obesity and type 2 diabetes. We provide evidence that SNARK mRNA expression is increased in skeletal muscle from obese normal glucose tolerant and type 2 diabetic men and women. The increase in SNARK mRNA was unaltered between normal glucose tolerant and type 2 diabetic individuals irrespectively of BMI, indicating the influence of obesity, rather than diabetes per se. Based on the phenotype of the Snarkhaploinsufficient mice [8], an increase in SNARK mRNA expression would be predicted to have a positive effect on energy and glucose homeostasis, but this does not appear to be the case, at least in humans. We also report that elevated levels of TNF- $\alpha$ or palmitate, systemic factors implicated in obesity-induced insulin resistance, increased $S N A R K$ expression in cultured human skeletal muscle myotubes. Nevertheless, a $60 \%$ reduction in SNARK mRNA by siRNA-mediated gene silencing (an effect similar to that achieved in whole-body Snark-haploinsufficient mice [8]), was without effect on basal or insulinstimulated glucose uptake and lipid oxidation. Furthermore, $S N A R K$ silencing did not prevent TNF- $\alpha$ - or palmitateinduced insulin resistance in skeletal muscle. Thus, while obesity and associated systemic factors, such as TNF- $\alpha$ or palmitate increase SNARK mRNA expression, insulin resistance induced by these factors occurs via a SNARKindependent mechanism.

Snark-haploinsufficient mice, with a 50\% reduction of whole-body Snark mRNA expression, develop obesity and insulin resistance, as evidenced by increased adiposity, fatty liver, increased serum triacylglycerol, hyperinsulinaemia, hyperglycaemia and glucose intolerance [8]. Thus, our findings of increased skeletal muscle SNARK mRNA expression in obese humans and in response to elevated levels of TNF- $\alpha$ or palmitate in vitro, suggest that the metabolic phenotype observed in total-body Snark-haploinsufficient mice is unlikely to arise from a direct effect of 
SNARK in skeletal muscle. Rather, these results implicate a role for SNARK in other tissues, particularly since skeletal muscle expresses relatively low levels of SNARK compared with liver, kidney, intestine and testis in rodents [11]. The development of mature-onset obesity in whole-body Snark-heterozygous mice might occur from a central defect that modifies food intake and activity levels, rather than a direct effect in peripheral tissues. The absence of a basal energetic defect in skeletal muscle of Snark-heterozygous mice, as well as an unexplained increased motivation/drive for voluntary exercise supports this contention [19]. Fibre type composition and number is unaffected in Snarkheterozygous mice, indicating Snark expression and activity in tissues other than skeletal muscle may contribute to the regulation of glucose and energy homeostasis and motivation for physical activity. For example, impairments in brown adipose tissue may contribute to the obesity phenotype, since whole-body temperature and energy expenditure was reduced in these mice. Further studies using tissue-specific Snark knockout mice may resolve this paradox.

The identification of an AMPK subfamily [3] raises questions about the involvement of these protein kinases in whole-body and cellular glucose and energy homeostasis, as well as the possibility that they might regulate cellular and whole-body metabolic and gene regulatory responses in a manner analogous to AMPK. Lkb1 (also known as Stk11) knockout mice have been important in the evaluation of the metabolic role of the AMPK-related kinases, since it is a master kinase that activates the majority of the members of this subfamily [3]. For example, contraction-mediated glucose uptake is inhibited in skeletal muscle from $L \mathrm{kbl}$ knockout mice [20] and kinase-dead $A m p k \alpha 2$ transgenic mice [21], but not Ampk $\alpha 1$ and Ampko2 isoform-specific knockout mice [22], indicating both AMPK-dependent and AMPK-independent pathways may play a role. Moreover, skeletal muscle-selective knockout of $L k b l$ increases whole-body and skeletal muscle insulin sensitivity and improves glucose homeostasis [7], implicating AMPKrelated protein kinases participate in the negative regulation of insulin action. Given our observation that SNARK mRNA expression was elevated in skeletal muscle from obese humans and myotubes exposed to TNF- $\alpha$ or palmitate, we tested the hypothesis that SNARK silencing would directly alter insulin action on glucose and lipid metabolism. However, neither basal nor insulin-stimulated glucose incorporation into glycogen was altered by SNARK silencing in primary human myotubes. Furthermore, basal, as well as insulin- or AICAR-stimulated beta oxidation was unchanged by SNARK silencing. This contrasts with earlier findings which revealed that $A M P K \alpha$ subunit silencing prevents the effects of IL-6 to promote beta oxidation into human myotubes [23]. Thus, AMPK, rather than SNARK, appears to control lipid oxidation in skeletal muscle.
Although siRNA against SNARK reduced mRNA expression by $60 \%$, we cannot exclude the possibility that a total knockout of SNARK may be required to reveal effects on glucose and lipid metabolism.

Our observation of increased SNARK mRNA expression in skeletal muscle from obese humans, and in response to TNF$\alpha$ or palmitate treatment, potentially connects SNARK to metabolic regulation in response to cellular stress signals. For example, TNF- $\alpha$ secretion from adipose tissue is increased and IL-6 serum levels are elevated in obese insulin-resistant individuals [24]. Thus, the intracellular communication between adipocytes or macrophages in obesity may provide stress signals that increase SNARK expression in skeletal muscle, which may modify insulin action. Nevertheless, siRNA against $S N A R K$ failed to prevent the development of TNF- $\alpha$ - or palmitate-induced insulin resistance on glucose incorporation into glycogen. Previous studies from our laboratory provide evidence that siRNAmediated reduction of either the mitogen-activated protein kinase kinase kinase kinase isoform 4 [15] or the inhibitor of nuclear factor-kappa $\beta$ (NF-K $\beta$ ) kinase [17] prevents TNF- $\alpha$ induced insulin resistance in human skeletal muscle. Interestingly, SNARK has anti-apoptotic properties, acting through a TNF- $\alpha$-sensitive nuclear NF- $K \beta$-mediated mechanism [25]. Thus, the increase in $S N A R K$ expression may be a consequence, rather than a cause of skeletal muscle insulin resistance.

In conclusion, we provide evidence against a role for SNARK in the regulation of skeletal muscle glucose or lipid metabolism. Nevertheless, obesity, but not type 2 diabetes, is associated with an increase in skeletal muscle SNARK mRNA expression in humans. This increase in SNARK mRNA expression may occur as a consequence of systemic factors associated with metabolic impairments in obesity, since exposure of myotubes to elevated levels of TNF- $\alpha$ or palmitate acutely increased SNARK mRNA expression. siRNA against SNARK failed to rescue TNF$\alpha$ - or palmitate-induced insulin resistance, indicating changes in SNARK expression occur as a consequence, rather than a cause of insulin resistance. Based on our findings in human skeletal muscle, and the insulin-resistant and obesity phenotype in whole-body Snark-haploinsufficient mice [8], SNARK expression in metabolically active tissues beyond skeletal muscle may play a role in wholebody energy and glucose homeostasis.

Acknowledgements This study was supported by grants from the European Research Council, the European Foundation for the Study of Diabetes, the Swedish Research Council, the Swedish Diabetes Association, the Strategic Research Foundation, the Knut and Alice Wallenberg Foundation, the Novo Nordisk Research Foundation and the Commission of the European Communities (Contract No LSHMCT-2004-005272 EXGENESIS and Contract No LSHM-CT-2004512013 EUGENE2). 
Duality of interest The authors declare that there is no duality of interest associated with this manuscript.

Open Access This article is distributed under the terms of the Creative Commons Attribution Noncommercial License which permits any noncommercial use, distribution, and reproduction in any medium, provided the original author(s) and source are credited.

\section{References}

1. Long YC, Zierath JR (2008) Influence of AMP-activated protein kinase and calcineurin on metabolic networks in skeletal muscle. Am J Physiol Endocrinol Metab 295:E545-E552

2. Hardie DG (2008) AMPK: a key regulator of energy balance in the single cell and the whole organism. Int J Obes (Lond) 32 (Suppl 4):S7-S12

3. Lizcano JM, Goransson O, Toth R et al (2004) LKB1 is a master kinase that activates 13 kinases of the AMPK subfamily, including MARK/PAR-1. EMBO J 23:833-843

4. Manning G, Whyte DB, Martinez R, Hunter T, Sudarsanam S (2002) The protein kinase complement of the human genome. Science 298:1912-1934

5. Al-Hakim AK, Goransson O, Deak M et al (2005) 14-3-3 cooperates with LKB1 to regulate the activity and localization of QSK and SIK. J Cell Sci 118:5661-5673

6. Sakamoto K, Goransson O, Hardie DG, Alessi DR (2004) Activity of LKB1 and AMPK-related kinases in skeletal muscle: effects of contraction, phenformin, and AICAR. Am J Physiol Endocrinol Metab 287:E310-E317

7. Koh HJ, Arnolds DE, Fujii N et al (2006) Skeletal muscleselective knockout of LKB1 increases insulin sensitivity, improves glucose homeostasis, and decreases TRB3. Mol Cell Biol 26:8217-8227

8. Tsuchihara K, Ogura T, Fujioka R et al (2008) Susceptibility of Snark-deficient mice to azoxymethane-induced colorectal tumorigenesis and the formation of aberrant crypt foci. Cancer Sci 99:677-682

9. Rosen CF, Poon R, Drucker DJ (1995) UVB radiation-activated genes induced by transcriptional and posttranscriptional mechanisms in rat keratinocytes. Am J Physiol 268:C846-C855

10. Lefebvre DL, Bai Y, Shahmolky N et al (2001) Identification and characterization of a novel sucrose-non-fermenting protein kinase/ AMP-activated protein kinase-related protein kinase, SNARK. Biochem J 355:297-305

11. Lefebvre DL, Rosen CF (2005) Regulation of SNARK activity in response to cellular stresses. Biochim Biophys Acta 1724:71-85

12. Egan B, Zierath JR (2009) Hunting for the SNARK in metabolic disease. Am J Physiol Endocrinol Metab 296:E969-E972
13. Kuga W, Tsuchihara K, Ogura T et al (2008) Nuclear localization of SNARK; its impact on gene expression. Biochem Biophys Res Commun 377:1062-1066

14. Al-Khalili L, Kramer D, Wretenberg P, Krook A (2004) Human skeletal muscle cell differentiation is associated with changes in myogenic markers and enhanced insulin-mediated MAPK and PKB phosphorylation. Acta Physiol Scand 180:395-403

15. Bouzakri K, Zierath JR (2007) MAP4K4 gene silencing in human skeletal muscle prevents tumor necrosis factor-alpha-induced insulin resistance. J Biol Chem 282:7783-7789

16. Al-Khalili L, Chibalin AV, Kannisto K et al (2003) Insulin action in cultured human skeletal muscle cells during differentiation: assessment of cell surface GLUT4 and GLUT1 content. Cell Mol Life Sci 60:991-998

17. Austin RL, Rune A, Bouzakri K, Zierath JR, Krook A (2008) siRNA-mediated reduction of inhibitor of nuclear factor-kappaB kinase prevents tumor necrosis factor-alpha-induced insulin resistance in human skeletal muscle. Diabetes 57:2066-2073

18. Sabin MA, Stewart CE, Crowne EC et al (2007) Fatty acidinduced defects in insulin signalling, in myotubes derived from children, are related to ceramide production from palmitate rather than the accumulation of intramyocellular lipid. J Cell Physiol 211:244-252

19. Ichinoseki-Sekine N, Naito H, Tsuchihara K et al (2009) Provision of a voluntary exercise environment enhances running activity and prevents obesity in Snark-deficient mice. Am J Physiol Endocrinol Metab 296:E1013-E1021

20. Sakamoto K, McCarthy A, Smith D et al (2005) Deficiency of LKB1 in skeletal muscle prevents AMPK activation and glucose uptake during contraction. EMBO J 24:1810-1820

21. Mu J, Brozinick JT Jr, Valladares O, Bucan M, Birnbaum MJ (2001) A role for AMP-activated protein kinase in contractionand hypoxia-regulated glucose transport in skeletal muscle. Mol Cell 7:1085-1094

22. Jorgensen SB, Viollet B, Andreelli F et al (2004) Knockout of the alpha2 but not alpha1 5'-AMP-activated protein kinase isoform abolishes 5-aminoimidazole-4-carboxamide-1-beta-4-ribofuranosidebut not contraction-induced glucose uptake in skeletal muscle. J Biol Chem 279:1070-1079

23. Al-Khalili L, Bouzakri K, Glund S, Lonnqvist F, Koistinen HA, Krook A (2006) Signaling specificity of interleukin-6 action on glucose and lipid metabolism in skeletal muscle. Mol Endocrinol 20:3364-3375

24. Kern PA, Ranganathan S, Li C, Wood L, Ranganathan G (2001) Adipose tissue tumor necrosis factor and interleukin- 6 expression in human obesity and insulin resistance. Am J Physiol Endocrinol Metab 280:E745-E751

25. Legembre P, Schickel R, Barnhart BC, Peter ME (2004) Identification of SNF1/AMP kinase-related kinase as an NFkappaB-regulated anti-apoptotic kinase involved in CD95induced motility and invasiveness. J Biol Chem 279:4674246747 